Atıf için / For Citation: M.Ş. Cansever, N. Öztekin, V. Adımcılar, T. Zübarioğlu, E. Kıykım, A.Ç. Aktuğlu-Zeybek "İdrarda Orotik Asit'in Temassız İletkenlik Dedektörü Kullanılarak Kapiler Elektroforez Yöntemi İle Hızlı Tayini”, Süleyman Demirel Üniversitesi Fen Edebiyat Fakültesi Fen Dergisi, 15(2), 194-202, 2020.

\title{
İdrarda Orotik Asit'in Temassız İletkenlik Dedektörü Kullanılarak Kapiler Elektroforez Yöntemi İle Hızlı Tayini
}

\author{
Mehmet Şerif CANSEVER $^{1 *}$, Nevin ÖZTEKİN ${ }^{2}$, Veselina ADIMCILAR ${ }^{2}$, \\ Tanyel ZÜBARIOĞLLU ${ }^{3}$, Ertuğrul KIYKIM ${ }^{4}$, Ayşe Çiğdem AKTUĞLU ZEYBEK ${ }^{4}$
}

\begin{abstract}
${ }^{I}$ Tekirdă̆ Namık Kemal Üniversitesi, Sağllk Hizmetleri Meslek Yüksek Okulu, Tibbi Hizmetler ve Teknikler Bölümü, Tıbbi Laboratuvar Teknikleri Programı, 59030, Süleymanpaşa, Tekirdağ, Türkiye ${ }^{2}$ Ístanbul Teknik Üniversitesi, Fen-Edebiyat Fakültesi, Kimya Bölümü, 34469 Maslak, İstanbul, Türkiye ${ }^{3}$ Sağllk Bilimleri Üniversitesi, Şişli Etfal Eğitim ve Araştırma Hastanesi, Çocuk Sağglı̆̆ ve Hastalıkları Ana Bilim Dal, 34371, İstanbul, Türkiye

${ }^{4}$ İstanbul Üniversitesi-Cerrahpaşa, Cerrahpaşa Tip Fakültesi, Çocuk Sağllğ̆ ve Hastallkları Ana Bilim Dal, Beslenme ve Metabolizma Bilim Dall, 34098, Fatih, İstanbul, Türkiye

*yazışllan yazar e-posta: mscansever@nku.edu.tr
\end{abstract}

(Alınış / Received: 28.02.2020, Kabul / Accepted: 08.06.2020, Yaylmlanma / Published: 29.11.2020)

Özet: İdrarda orotik asidin aşırı atılımı üre döngüsü bozukluğu ve pirimidin sentez bozukluğu gibi doğumsal metabolik hastalıklarda görülür. Bu nedenle yenidoğan döneminde orotik asidin hızlı bir șekilde tayini hayati öneme sahiptir. İdrarda orotik asit düzeyi ölçümü için mevcut yöntemler hem zaman alıcı hem de pahalı yöntemlerdir. Bu çalışmada idrar örneklerinde orotik asidin kantitatif düzeylerinin belirlenmesi için yeni, basit, ucuz ve hızlı bir kapiler elektroforetik analiz yöntemi geliştirildi. Orotik asidin temassız iletkenlik dedektörü $\left(\mathrm{C}^{4} \mathrm{D}\right)$ kullanılarak kapiler elektroforez yöntemi ile ayrımı için pH'1 6,5 olan $20 \mathrm{mM}$ 4-Morfolinetansülfonik asit (MES), $10 \mathrm{mM}$ Histidin ve 0,1 mM Setil trimetilamonyum bromür (CTAB) içeren bir çalışma tamponu ile geliştirildi. Orotik asidin ayrılması yaklaşık 3,5 dakika gibi kısa bir sürede tamamlandı. Göç zamanlarının ve düzeltilmiş pik alanlarının tekrarlanabilirliği sırasıyla \%RSD olarak 1,25 ve 4,31 olarak bulundu. En düşük dedeksiyon limiti (LOD) $0,733 \mathrm{mg} / \mathrm{L}$ ve en düşük tayin limiti de (LOQ) 2,443 mg/L olarak bulundu. Geliştirilen yöntemin idrarda orotik asit düzeylerinin tayin edilmesinde kolaylıkla ve hassasiyetle kullanılabileceği gösterildi.

Anahtar Kelimeler: Kapiler Elektroforez, Orotik Asit, Temassız İletkenlik Dedektörü $\left(C^{4} D\right)$, Üre Döngüsü Bozuklukları, Doğumsal Metabolik Hastalık, İdrar

\footnotetext{
Mehmet Şerif CANSEVER, mscansever@ nku.edu.tr, ORCID: https://orcid.org/0000-0003-3315-5124 Nevin ÖZTEKIN, noztekin@itu.edu.tr, ORCID: https://orcid.org/0000-0003-3676-5147 Veselina ADIMCILAR, adimcilar@itu.edu.tr, ORCID: https://orcid.org/0000-0002-7016-1200 Tanyel ZÜBARİĞLU, tanye10554@yahoo.com, ORCID: https://orcid.org/0000-0002-7159-4008 Ertuğrul KIYKIM, ertugrulkiykim@ hotmail.com, ORCID: https://orcid.org/0000-0001-5170-5594 Ayşe Çiğdem AKTUĞLU ZEYBEK, dracaz@istanbul.edu.tr, ORCID: https://orcid.org/0000-00017256-0750
} 


\title{
Rapid Determination Of Orotic Acid Level In Urine By Capillary Electrophoresis Coupled With Contactless Conductivity Detection
}

\begin{abstract}
Excessive excretion of orotic acid in urine arises as a result of some inborn metabolic diseases such as urea cycle disorders and pyrimidine synthesis disorders. Therefore, rapid determination of orotic acid in the neonatal period is vital. Existing methods for measuring orotic acid levels in urine are both time consuming and expensive. Consequently, rapid definition of the orotic acid level in human urine is important. In this current study a novel, simple, cost effective and rapid (fast) capillary electrophoretic analysis method was developed for quantitative measurement of orotic acid content in urine samples. Determination of orotic acid by employing capillary electrophoresis coupled with contactless conductivity detection was achieved by using, $20 \mathrm{mM}$ 4-Morpholineethanesulfonic acid (MES), $10 \mathrm{mM}$ Histidine, $0.1 \mathrm{mM}$ Cetyltrimethylammonium Bromide (CTAB) at $\mathrm{pH}$ of 6.5 as optimum electrolyte solution. Orotic acid was well separated from the sample constituents within a short analysis time less than 3.5 minutes. The precisions for the migration times and corrected peak areas were calculated as 1.25 and 4.31 RSD\% respectively. Limit of detection and limit of quantification of the proposed method were also calculated as $0.733 \mathrm{mg} / \mathrm{L}$ and $2.443 \mathrm{mg} / \mathrm{L}$ respectively. The developed sensitive and facile capillary electrophoresis method was validated and applicability of the method was successfully demonstrated by assessment of orotic acid content in urine.
\end{abstract}

Keywords: Capillary Electrophoresis, Orotic Acid, Contactless Conductivity Detection $\left(\mathrm{C}^{4} \mathrm{D}\right)$, Urea Cycle Disorders, Inborn Metabolic Disease, Urine. 


\section{Giriş}

İnsanlarda pirimidin de novo sentezi sitozolik karbomoil fosfat sentetaz (CPS) enzimi II vasıtasıyla glutamin ve bikarbonattan karbomoil fosfat oluşumu ile başlar [1]. Üre döngüsünün hız kısıtlayıcı basamağı olan karbomoil fosfat sentetaz I enzimi ise mitokondride görev alır. Orotik asid insanlarda pirimidin sentezinin dördüncü basamağında dihidrorat dehidrogenaz enzimi ile sentezlenir. Sentezlenmiş olan orotik asit üridin monofosfat (UMP) sentetaz vasıtasıyla UMP'ye dönüşür $[2,8]$.

Üridin monofosfat sentetaz eksikliği herediter orotik asidüriye sebep olur. Hastalık çoğu zaman doğumdan sonraki birkaç ay içerisinde başlayan, demir ve $\mathrm{B}_{12}$ vitamin tedavisine dirençli megaloblastik anemi ile bulgu verir. Tedavi edilmeyen hastalarda büyüme gelişme geriliği ve zekâ geriliği gelişir. Hastalıkta tanı idrarda normalin 200-1000 katı artmış olan orotik asidin saptanması ve genetik analizle doğrulanır. Tedavi, enzim eksikliğinin bulunduğu basamağın bir sonraki basamağında üretilen üridin ile yapılır $[3,4]$ Mitokondriyal karbomoil fosfat sentetaz I enzimi yardımıyla oluşan karbomoil I fosfat da de novo pirimidin sentezini arttırarak üre döngüsü bozukluklarının bir kısmında orotik asit artışına neden olur. Özellikle aynı klinik ve laboratuvar bulguları olan N-asetil glutamat sentetaz (NAGS) eksikliği, CPS 1 eksikliği ve ornitin transkarbamilaz (OTC) eksikliğinin ayırıcı tanısında kullanılmaktadır. N-asetil glutamat sentetaz ve CPS 1 enzim eksikliklerinde CPS üretilemediği için orotik asit atılımı olmazken, OTC eksikliğinde idrarda orotik asit atılımı saptanır $[5,6]$.

İdrarda orotik asit artışı doğumsal metabolik hastalıklar dışında allopürinol ve 6azaüridine gibi pirimidin metabolizmasını etkileyen ilaçların kullanımında da gözlenebilir $[7,8]$. İdrarda orotik asit ölçümü plazmadan daha önemli olduğu belirlenmiştir. İdrarda orotik asit analizi için günümüze kadar literatürde birkaç analitik yöntem bildirilmiştir [9,10]. Biyolojik örneklerde orotik asitin ölçülmesi zordur ve genellikle ileri aletli analiz teknikleri gerektirir. Analiz için kullanılan analitik yöntemler, yüksek basınçlı sıv1 kromatografisi (HPLC) [11,12], sıv1 kromatografisi ardışık kütle spektrometresi (LC/MS/MS) [13-15], gaz kromatografisi kütle spektrometresi (GC/MS) [16], kapiler zon elektroforez ultraviyole dedektör (CZE-UV) [17,18], spektrofotometre ve spektroflorometre [19] olarak bildirilmiştir. Bu analitik araçlar ileri teknoloji ürünleri olsa da pahalı olmaları, uzun analiz sürelerine sahip olmaları, türevlendirmeye ihtiyaç duymalar1, kullanılan organik maddelerin ve ön ayrıştırma işleminin uzun olması ve oluşturdukları atıkların toksik olması gibi olumsuzlukları vardır. Kapiler elektroforez, diğer ileri aletli analitik yöntemlerine göre, yüksek ayırma gücü, ucuz test maliyeti, kısa analiz süresi, kolay yöntem gelişimi, çoğu zaman numunelerde ön işlem gerektirmeden direkt enjeksiyona uygun, çok çok az numune enjeksiyonu, düşük miktarda çalışma tamponu gereksinimi ve atıkları bakımından çevre dostu olması gibi avantajlara sahiptir [20-24]. Günümüzde, temassız iletkenlik dedektörü $\left(C^{4} D\right)$ kapiler elektroforetik yöntemler için alternatif bir dedektör olarak kullanılmaya başlanmıştır [25]. $\mathrm{C}^{4} \mathrm{D}$ hem UV absorpiyona sahip hem de UV absorpsiyona sahip olmayan çeşitli türlerin tayini için oldukça uygun bir tayin yöntemidir. Diğer tayin teknikleri ile karşılaştırıldığında basit ve ucuz bir detektördür [26-28]. Bu dedektörde düşük iletkenlik gereksiniminden dolayı iletkenlik dedeksiyonu için iki zwitter iyonik bileşik içeren pH's1 6,0 olan MES ve Histidin tamponları kullanılır [29-31]. Bu çalışmada idrar örneklerindeki orotik asidin kantitatif tayini için yeni, basit, ucuz ve hızlı bir kapiler elektroforetik analiz yöntemi geliştirildi. 


\section{Materyal ve Metot}

\section{1. Kullanulan kimyasallar ve sentetik idrar}

MES (2-(N-Morpholino)ethanesülfonik asit, 4-Morfolinetansülfonik asit ) ve Histidin, Arjinin, CTAB Merck'den (Darmstadt, Germany), $\mathrm{NaOH}$ ve Orotik asit ( Sigma, St Louis)' den temin edildi. Çalışmada kullanılan sentetik (yapay) idrar, Artificial Urine, Pickering Laboratories (Mountain View, California, USA)' dan alındı. Sentetik idrar pH's1 6,5 olan gerçek insan idrarına benzer aynı bileşime sahip standart laboratuvar çalışmalarında kullanılan kullanıma hazır ve stabil bir çözeltidir. Bu çalışmada kullanılan çözeltiler, Elga Purelab marka Option-7-15 model saf su sisteminden elde edilen ultra saf su kullanılarak hazırlandi.

\subsection{Cihazlar}

Analitin tespiti, Prince Technologies marka (Emmen, Netherlands) kapiler elektroforez cihazı ile yapıldı. Dedektör olarak, Trace Dec marka temassız iletkenlik dedektörü kullanıldı. Elde edilen verilerin değerlendirilmesi DAx 8.0 Data Acquisition and Analysis işletim programı kullanılarak yapıldı. Çalışma için gerekli çözeltilerin tamamı Elga Purelab Option marka 7-15 model sistemi ile elde edilen ultra saf su kullanılarak hazırland1. Çalışma tamponunun pH' s1 Thermo Scientific marka Orion Dual Star model pH metre cihazı kullanılarak ayarlandı. Çalışmada kullanılan kapiler kolonlar Polymicro Technologies (Phoenix, AZ, Amerika) firmasından temin edildi. Bu yöntemde enjeksiyon öncesi numunelerin tamamı $0,45 \mu \mathrm{m}$ ' l1k gözeneğe sahip mikro filtre yardımıyla süzülerek sisteme enjekte edildi.

\section{3. Çaltşma Tamponu ve Optimum Koşullar}

Çalışma tamponu, $20 \mathrm{mM}$ 4-Morfolinetansülfonik asit (MES), $10 \mathrm{mM}$ Histidin, 0,1 mM CTAB, pH' s1 6,5 olarak optimize edildi. Uygulanan voltaj $-28 \mathrm{kV}$, enjeksiyon hacmi 100 mbar 0,1 dakika olarak tespit edildi. Ayırım için $50 \mu \mathrm{m}$ iç çaplı, etkin uzunluğu 65 $\mathrm{cm}$ toplam kolon uzunluğu $80 \mathrm{~cm}$ olan silika kapiler kolon kullanıldı. Bu çalışma tamponu ve optimize edilmiş koşullardan elde edilen elektroforeogram Şekil 1' de gösterilmişstir.

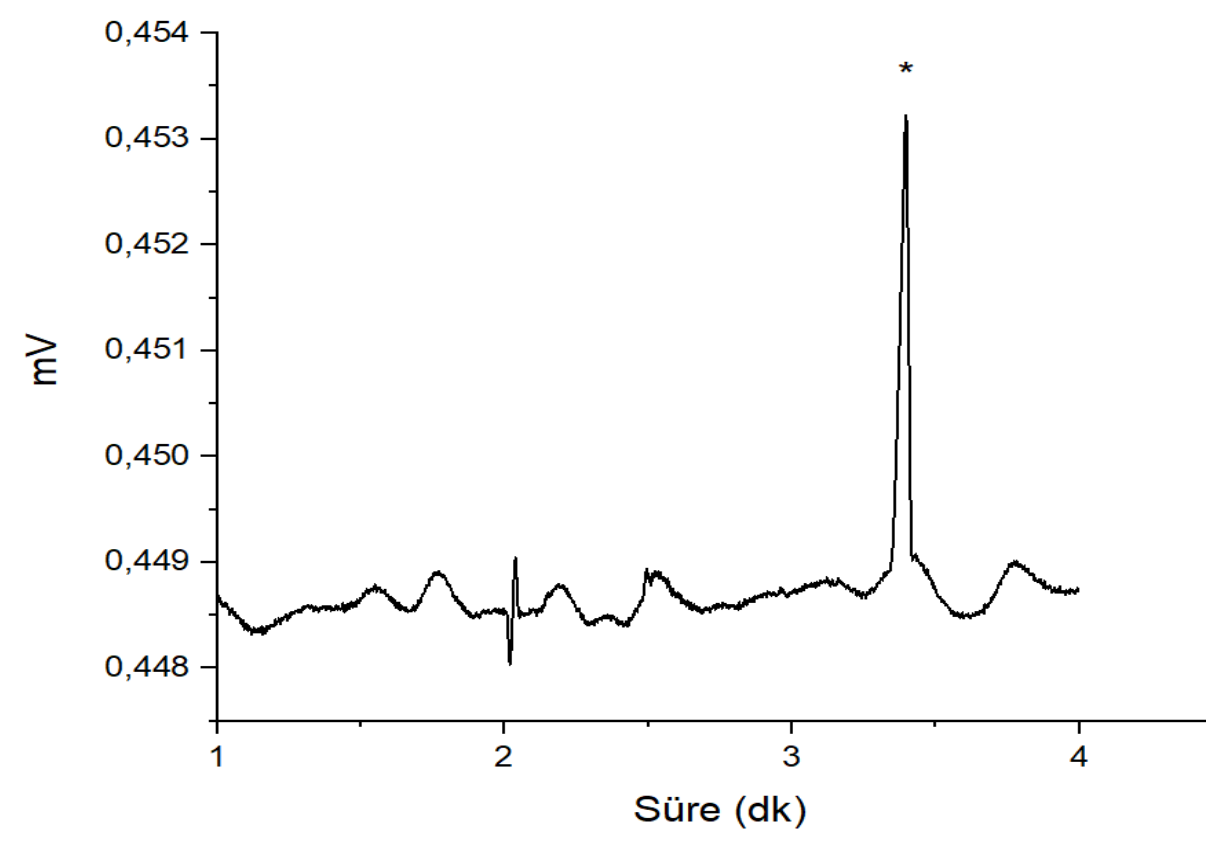


Şekil 1. Optimize edilmiş tampon çözelti ortamında, $100 \mathrm{mg} / \mathrm{L}$ standart orotik asit pikinin elektroforeogrami*.

\subsection{Numune Hazırlama}

İdrar numuneleri enjeksiyon öncesi 100 kat (1:100) distile su ile seyreltildi (v/v). Elde edilen numune $0,45 \mu \mathrm{m}$ ' lık gözenek çaplı mikro filtreden süzülerek cihaza enjekte edildi. Bu çalışmada numuneye ön işlem uygulanmaksızın sisteme direkt olarak numune enjeksiyonu amaçlanmıştır. İdrar numunesi matriks özelliğe sahip olduğundan dolayı bu etkiden kurtulmak için numune seyreltmeye ihtiyaç duyuldu. İdrar numunesinin $100 \mathrm{~kat}$ seyreltilmesi istenmeyen matriks özelliğini ortadan kaldırdığı gibi aynı zamanda orotik asit düzeylerinin belirlenmesinde kolaylık sağladığı görüldü.

\section{Bulgular}

Orotik asit (uracil-6-karboksilik asit), molekül ağırlığı 156,1 g/mol olan, ayrışma sabitleri $\mathrm{pK}_{\mathrm{a} 1}=2,07 ; \mathrm{pK}_{\mathrm{a} 2}=9,45$ olan, suda çözünebilen bir karboksilik asittir (Şekil 2).

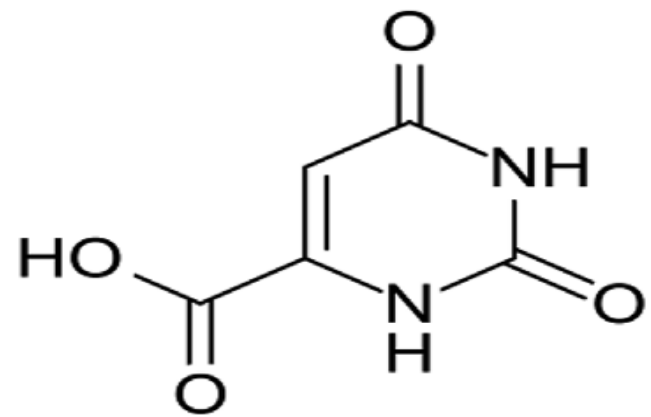

Şekil 2. Orotik Asit (uracil-6-karboksilik asit) 'in kimyasal yapısı

Kapiler elektroforezde, genel olarak örneğin pozitif kutuptan enjekte edilerek, analitlerin negatif kutup tarafına yerleştirilen detektör tarafına elektroosmotik akış ile sürüklenmesi olayına dayanır. Elektroosmotik akış ile sürüklenme esnasında analitlerin yük / büyüklük oranlarına göre hareketleri gözlenir. Kapiler kolon içinde oluşan elektroosmotik akışın mobilitesi analitik bileşiklerin elektroforetik mobilitesinden çok büyük olduğundan tüm analitler yüklerine bakılmaksızın detektör yönüne yani negatif kutuba göç ederler. Anorganik anyonlar ve küçük moleküllü organik asitler bu kurala uymazlar. Bu bileşiklerin kendi elektroforetik mobiliteleri oldukça yüksek olduğundan elektroosmotik akışın bu türlerinin dedektöre sürüklemesi uzun zaman alır. Bu sebepten dolayı bu tür analitler için kapilerin iç yüzeyini pozitif yükle kaplamak gerekir. İç yüzey kaplama sonras1 enjeksiyonu da negatif kutuptan yapmak gereklidir. Böylece elektroosmotik akışın yönünü negatif elektrottan pozitif elektroda doğru çevrilmiş ve aynı zamanda polariteyi değiştirmiş olur. Bu şekilde bu iyonların elektroforetik mobilitelerinin göç yönleri ile elektroosmotik mobilitenin akış yönü aynı yönde olacağından çok hızlı bir ayırma sağlanır [20-23]. Orotik asitin molekül yapısı elektroforetik mobilitesinin yüksek olacağı bilindiğinden dolayı kapiler kolon setiltrimetilamonyumbromür (CTAB) ile kaplandı. 20 mM MES, 10 mM Histidin, 0,1 mM CTAB, pH' sı 6,5 olan çalışma tamponunda orotik asitin sulu çözeltideki ve idrar ortamındaki elektroferogramlarından görüldüğü gibi orotik asit yaklaşık 3,5 dakikada tespit edildi (Şekil 1 ve 3). 


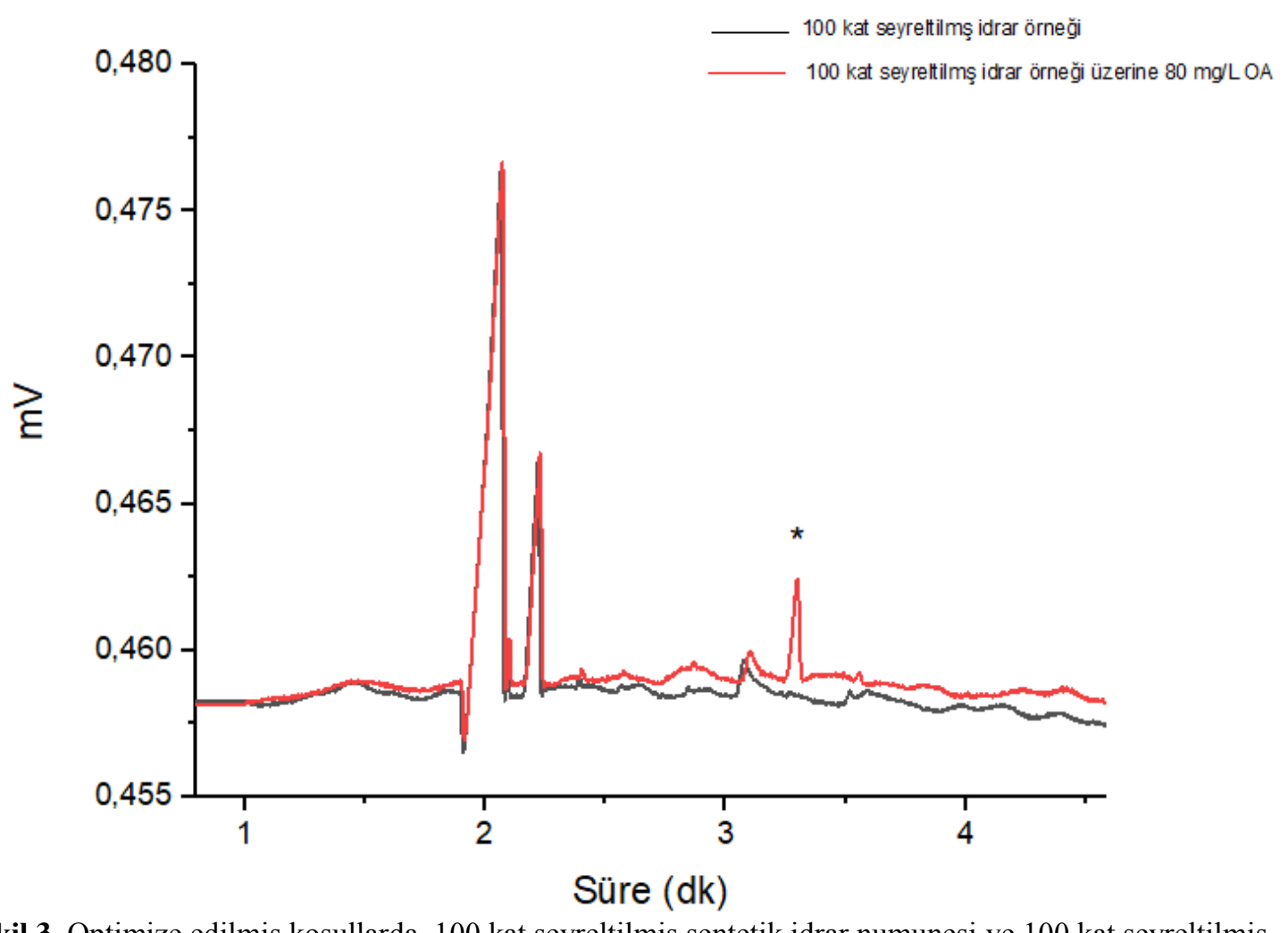

Şekil 3. Optimize edilmiş koşullarda, 100 kat seyreltilmiş sentetik idrar numunesi ve 100 kat seyreltilmiş sentetik idrar numunesine ilave edilen $80 \mathrm{mg} / \mathrm{L}$ konsantrasyonunda orotik asidin karşılaştırılmış elektroferogramlari*.

\subsection{Yöntem Validasyonu}

\subsubsection{Lineer Aralı, $L O D$ ve $L O Q$,}

Kalibrasyon doğrusu saf suda ve 100 kat seyreltilmiş idrarda 2,$5 ; 5 ; 10 ; 20 ; 40 ; 80$ ve $100 \mathrm{mg} / \mathrm{L}$ orotik asit konsantrasyon aralığında düzeltilmiş pik alanlarına (A/t) karşı çizilmiştir. Bu sınırlarda kalibrasyon denklemi için elde edilen regresyon parametreleri Tablo 1' de verilmiştir. Elektroforeogramda üç farklı bölgeden tespit edilen gürültünün, üç katı sinyal değeri minumum dedeksiyon limiti (LOD) olarak kabul edilerek, bu değer $0,733 \mathrm{mg} / \mathrm{L}$ orotik asit olarak bulundu. Kantitatif olarak minumum belirlenebilme sin1r1 (LOQ) değeri gürültü sinyalinin 10 katı olarak 2,443 mg / L olarak bulundu (Tablo 1). Elde edilen bu değer ilgili literatürde belirtilen normal yenidoğan bebeklerde beklenen normal değerin alt sınırı olan $78 \mathrm{mg} / \mathrm{L}$ ' nin çok altında olduğu görülmüştür. [32].

Tablo 1. Regresyon parametreleri, gözlenebilme sınırı ve tayin sınırı

\begin{tabular}{|c|c|c|}
\hline Regresyon parametreleri & İdrarda & Sulu çözeltilerde \\
\hline Regresyon katsayısı ( $\mathbf{R}^{2}$ ) & 0,999 & 0,999 \\
\hline Lineer aralık (mg/L) & $2,5-100$ & $2,5-100$ \\
\hline Ĕğim \pm SD & $2,22 * 10^{-6} \pm 1,28 * 10^{-8}$ & $1,89 * 10^{-6} \pm 7,25 * 10^{-8}$ \\
\hline Kesişim \pm SD & $-5,12 * 10^{-6} \pm 6,63 * 10^{-7}$ & $-7,4 * 10^{-6} \pm 3,73 * 10^{-6}$ \\
\hline Gözlem sayısı & 7 & 7 \\
\hline $\begin{array}{c}\text { Gözlenebilme sınırı } \\
(\mathrm{mg} / \mathrm{L})\end{array}$ & 0,733 & \\
\hline Tayin sınırı (mg/L) & 2,443 & \\
\hline
\end{tabular}




\subsubsection{Matriks Etkisi}

Matriks etkisi, matriks uyumlu kalibrasyon eğrisi ile saf çözücü kalibrasyon eğrisinin eğimlerinin oranından hesaplanarak incelenmiştir. Matriks uyumlu kalibrasyon için 100 kat seyreltilmiş idrar ve saf çözücü kalibrasyonu için ise ultrasaf su kullanıldı. Matriks etkisi \% 17 olarak bulundu. Bu değer \% -10 ile \% 10 arasında bulunmadığı için, matriks etkisinin önemli olduğu görülmektedir (Şekil 3).

\subsubsection{Tekrarlanabilirlik}

Yöntemin kesinliği 5, 10, 40 ve $100 \mathrm{mg} /$ L orotik asit standart çözeltisinin 7 defa artarda enjeksiyonu sonucu kontrol edildi. Göç zamanları ve düzeltilmiş pik alanları (A/t) için kesinlik değerleri gün içi ve günler arası kesinlik değerleri \% RSD olarak Tablo 2'de verilmiştir.

Tablo 2. Optimize edilmiş koşullarda, sentetik idrar numunelerinden elde edilen tekrarlanabilirlik ve geri

\begin{tabular}{|c|c|c|c|c|c|}
\hline \multirow[b]{2}{*}{$\begin{array}{c}\text { Eklenen miktar } \\
\mathrm{mg} / \mathrm{L}\end{array}$} & \multirow[b]{2}{*}{$\begin{array}{c}\text { Geri } \\
\text { kazanım } \\
\%\end{array}$} & \multicolumn{2}{|c|}{$\begin{array}{c}\text { Tekrarlanabilirlik Gün İçi } \\
(\mathbf{n}=7), \% \text { RSD }\end{array}$} & \multicolumn{2}{|c|}{$\begin{array}{c}\text { Tekrarlanabilirlik Günler } \\
\text { Arası }(n=21), \% \text { RSD } \\
\end{array}$} \\
\hline & & Zaman & $\begin{array}{l}\text { Düzeltilmiş } \\
\text { Alan }\end{array}$ & Zaman & $\begin{array}{l}\text { Düzeltilmiş } \\
\text { Alan }\end{array}$ \\
\hline 5 & 88 & 1,29 & 4,28 & 3,68 & 5,58 \\
\hline 10 & 96 & 1,16 & 4,35 & 3,43 & 5,67 \\
\hline 40 & 95 & 1,21 & 4,38 & 3,29 & 5,84 \\
\hline 100 & 92 & 1,25 & 4,31 & 3,52 & 5,72 \\
\hline
\end{tabular}

\subsubsection{Yöntemin doğruluğu,}

Yöntemin doğruluğu, üç ayrı konsantrasyonda; 5, 10, ve $40 \mathrm{mg}$ / L orotik asit standartları sırasıyla idrar örneğine ilave edilerek her biri için ayrı ayrı 7 farklı ölçüm alınarak yapıldı. Geri kazanım değerleri \% 88 ile 96 arasında bulundu (Tablo 2).

\section{Sonuç ve Yorum}

Sonuç olarak, idrarda orotik asit düzeyinin hızlı bir şekilde tayini özellikle orotik asit atılımını fazla olduğu hastalarda hayati bir önem taşımaktadır. Kapiler elektroforeztemassız iletkenlik dedektörü $\left(\mathrm{CE}-\mathrm{C}^{4} \mathrm{D}\right)$ ile orotik asit tayini kolay, hızlı, az madde kullanımı, herhangi bir türevlendirme işlemi gerektirmeyen, kolay numune hazırlığı, kullanılan çözeltiler ve miktarları bakımında çevre dostu, elde edilen sonuçlar bakımından hassasiyeti yüksek bir yöntem olarak bulunmuştur. Kapiler elektroforez ile yapılan çalışmalarda kullanılan numune hacmi nanolitre düzeyinde iken diğer yöntemlerde en az mikrolitre ile mililitre arasındadır. Geliş zamanlarına bakılacak olursa 3,5 dakika gibi bir sürede tespit sağlanırken diğer analiz yöntemlerine göre daha avantajlı olduğu görülmüştür. Orotik asidin rutin analizlerinde ve klinik araştırmalarında kullanılabileceği ortaya konulmuştur. 


\section{Araştırmacıların Katkı Oranı Beyanı}

Mehmet Şerif Cansever: Araştırma, Orijinal Taslak Yazımı, Metodoloji, Proje Yönetimi.

Nevin Öztekin: Doğrulama, İnceleme ve Düzenleme, Veri İyileştirme.

Veselina Adımcılar: Kaynak/Materyal/Malzeme Temini, Doğrulama, Yazılım.

Tanyel Zübarioğlu: Kaynak/Materyal/Malzeme Temini, Görselleştirme.

Ertuğrul Kıykım: Kaynak/Materyal/Malzeme Temini, Yazılım.

Ayşe Çiğdem Aktuğlu-Zeybek: Denetim/Gözlem/Tavsiye, Biçimsel Analiz.

\section{Destek ve Teşekkür Beyanı}

$\mathrm{Bu}$ çalışmanın yazarları olarak herhangi bir destek ve teşekkür beyanımız bulunmadığını bildiririz.

\section{Çatışma Beyanı}

$\mathrm{Bu}$ çalışmanın yazarları olarak herhangi bir çatışma beyanımız bulunmadığını bildiririz.

\section{Etik Kurul Onayı ve/veya Aydınlatılmış Onam Bilgileri}

$\mathrm{Bu}$ çalışmanın yazarları olarak herhangi bir etik kurul onayı ve/veya aydınlatılmış onam bilgileri beyanımız bulunmadığını bildiririz.

\section{Kaynakça}

[1] M. Duran, L. Dorland, E. E. Meuleman, P. Allers, R. Berger, "Inherited defects of purine and pyrimidine metabolism: laboratory methods for diagnosis," J Inherit Metab Dis 20, 227-236, 1997.

[2] M. Loeffler, E. Zameitat, "Pyrimidine biosynthesis", Encycl Biol Chem, 3, 600-605, 2004.

[3] S. Balasubramaniam, J.A. Duley, J. Christodoulou, "Inborn errors of pyrimidine metabolism: clinical update and therapy," J Inherit Metab Dis, 37(5):687-98, 2014.

[4] R.E. Kelley, H.C. Andersson, "Disorders of purines and pyrimidines," Handb Clin Neurol., 120, 82738, 2014.

[5] J. Häberle, N. Boddaert, A. Burlina, A. Chakrapani, M. Dixon, M. Huemer, D. Karall, D. Martinelli, P.S. Crespo, R: Santer, A. Servais, V. Valayannopoulos, M. Lindner, V. Rubio disorders, "Orphanet J Rare Dis, 29, 7-32, 2012.

[6] C. Bachmann, J.P. Colombo. "Diagnostic value of orotic acid excretion in heritable disorders of the urea cycle and in hyperammonemia due to organic acidurias," Eur J Pediatr., 134(2):109-13,1980.

[7] S.W. Brusilow, E. Hauser. "Simple method of measurement of orotic acid and orotidine in urine," $J$. Chromatogr. B Biomed. Sci. Appl., 1;493(2), 388-91, 1989.

[8] M. Löffler, E.A. Carrey , E. Zameitat. "Orotic Acid, More Than Just an Intermediate of Pyrimidine de novo Synthesis". J Genet Genomics., 20, 42(5), 207-19, 2015.

[9] C. Salerno, C. Crifò, "Diagnostic value of urinary orotic acid levels: applicable separation methods,' J. Chromatogr. B. Analyt. Technol. Biomed. Life Sci., 781, 57-71, 2002.

[10] S. Yin, S. Dragusha, V. Ejupi, T. Shibata, T. Kabashima, M. Kai, "Sensitive and selectivedetermination of orotic acid in biological specimens using a novel fluorogenicreaction," J. Fluoresc., 25, $1005-1011,2015$.

[11] A. Fioravanti, M. Flaviani, C. Gambelunghe, A. Micheletti, M. Sposito, S. Rufini, "Highperformance Liquid Chromatographic Determination of Orotic Acid as its Methyl Derivative in Human Urine"' J Chromatogr. B, Biomed. Sci. Appl., 703, 263-266, 1997.

[12] B. Tavazzi, G. Lazzarino, P. Leone, A.M. Amorini, F. Bellia, C.G. Janson, et al., "Simultaneous high performance liquid chromatographic separation of purines, pyrimidines, $\mathrm{N}$-acetylated amino acids, and dicarboxylic acids for the chemical diagnosis of inborn errors of metabolism," Clin. Biochem. 38, 997-1008, 2005.

[13] M.S. Rashed, M. Jacob, M. Al-Amoudi, Z. Rahbeeni, M.A.D. Al-Sayed, L. Al-Ahaidib, et al., "Rapid determination of orotic acid in urine by liquid chromatography-electrospray tandem mass spectrometry," Clin. Chem., 49, 499-501, 2003.

[14] G. la Marca, B. Casetta, E. "Zammarchi, Rapid determination of orotic acid in urineby a fast liquid chromatography/tandem mass spectrometric method", Rapid Commun. Mass Spectrom., 17, 788793, 2003.

[15] O. D'Apolito, D. Garofalo, G. Paglia, A. Zuppaldi, G. Corso, "Orotic acid quantification in dried blood spots and biological fluids by hydrophilic interaction liquid chromatography tandem mass spectrometry", J. Sep. Sci., 33, 966-973,2010.

[16] R. Hušková, P. Barták, L. Čáp, D. Friedecký, T. Adam, “Analytical derivatization-a tool for determination of orotic acid", J. Chromatogr. B Anal. Technol. Biomed. Life Sci. 799, 303-309,2004.

[17] O. Giardini, C. Salerno, P. D. Eufemia, M. Celli, R. Finocchiaro, C. Crifo, "Determination of urinary orotic acid and uracil by capillary zone electrophoresis", J. Chromatogr. B., 734, 175-178,1999. 
[18] J. Sevcík, T. Adam, V. Sázel, “A rapid and simple screening method for detection of orotic aciduria by capillary zone electrophoresis,' Clin. Chim. Acta, 259,73-81, 1997.

[19] H. Khajehsharifi, H. Tavallali, M. Shekoohi, M. Sadeghi, "Spectrophotometric simultaneous determination of orotic acid, creatinine and uric acid by orthogonal signal correction-partial least squares in spiked real samples', Drug Test. Anal., 5, 353-360, 2013.

[20] J. W. Jorgenson, K. D. Lukacs, "Zone electrophoresis in open-tubular glass capillaries," Anal. Chem., 53, 1298-1302,1981.

[21] J. W. Jorgenson, K. D. Lukacs. "Free-zone electrophoresis in glass capillaries," Clinical Chemistry, 27, 1551-1553, 1981.

[22] J. W. Jorgenson, K. D. Lukacs, "High-resolution separations based on electrophoresis and electroosmosis," J. Chromatogr. A, 218, 209-216, 1981.

[23] S. F. Y., Capillary Electrophoresis. Amsterdam: Elsevier, 1992.

[24] S. Özden, R. Ertan, E. Akı-Şener, G. Yalçın, Farmasötik Kimya Pratikleri. Ankara. Ankara Üniversitesi, Eczacilık Fakültesi, 1-2, 2004.

[25] P. Kubáň, P. C. Hauser, "Contactless conductivity detection in capillary electrophoresis: A review," Electroanalysis, 16(24), 2009-2021, 2004.

[26] A. J. Zemann, E. Schnell, D. Volgger, G. K. Bonn, "Conductivity detection for capillary electrophoresis," Anal. Chem., 70(3), 563-567, 1998.

[27] H.E. Yelkenci, N. Öztekin, "Separation and Sensitive Detection of Lanthanides by Capillary Electrophoresis and Contactless Conductivity Detection,' J. Chromatogr. Sci., 55 (4), 465- 470, 2017.

[28] P. Kubáň, P. C. Hauser, "Review: Capacitively coupled contactless conductivity detection for microseparation techniques-recent developments, ” Electrophoresis, 32, 30-42, 2011.

[29] P.Kubáň, P. C. Hauser, "Ten years of axial capacitively coupled contactless conductivity detection for CZE - a review,” Electrophoresis, 30, 176-188, 2009.

[30] P. Kubán̆, P. C. Hauser, "A review of the recent achievements in capacitively coupled contactless conductivity detection," Anal. Chim. Acta., 607(1), 15-29, 2008.

[31] A. A. Elbashir, H. Y. Aboul-Enein, "Recent advances in applications of capillary electrophoresis with capacitively coupled contactless conductivity detection $\left(\mathrm{CE}-\mathrm{C}^{4} \mathrm{D}\right)$ : An update," Biomed. Chromatogr., 26, 990-1000, 2012.

[32] O. D'Apolito, D. Garofalo, G. La Marca, A. Dello Russo, G. Corso, "Reference intervals for orotic acid in urine, plasma and dried blood spot using hydrophilic interaction liquid chromatographytandem mass spectrometry", J. Chromatogr. B., (1) 883-884, 155-160, 2012. 